\title{
Study of the Role of NGO in Strengthening the Food Safety and Construction of the Relevant Law
}

\author{
Yang Yang \\ Southwest University, Chongqing, China \\ Email: yangyangtangxin@vip.qq.com
}

Received 10 May 2014; revised 11 June 2014; accepted 29 June 2014

Copyright (C) 2014 by author and Scientific Research Publishing Inc.

This work is licensed under the Creative Commons Attribution International License (CC BY). http://creativecommons.org/licenses/by/4.0/

(c) () Open Access

\begin{abstract}
Food safety, which is a key part of livelihood projects, is not only closely related to the thousands of households table, but enormously affecting the whole country. The government departments as the manager of the public interests have been committed to strengthen the construction of food safety, but its results are always unremarkable. In order to prevent "the government failure" in the process of food supervision, the food NGO is now entering the people's view. It has a comparative advantage in specialization, independence and efficiency, however, as an emerging force, it is also plagued by problems such as small number, weak power, lack of necessary support in law and so on. Therefore, the food NGO might be worth a great depal; it is essential for the system construction especially the construction of relevant Law apart from continuous development and ceaseless accumulation.
\end{abstract}

\section{Keywords}

The Food Safety, The Government Failure, The Food NGO

\section{Introduction}

Food is the paramount necessity of people, safety is the priority of food. Even though a wide cross-section of society has been calling for strengthening the construction of food safety, especially after the appearance of the melamine incident, the supervision department to food safety makes a great effort to rectify the food business of production and sales, the food safety incidents still remain frequent and numerous like the wave and even some reporters openly declared that China has entered a mutual poisoning era. Under the economic factors and no belief, everything is going to be used for the commercial interests. We are surrounded by various hormone, pesti- 
cide and chemical products, such as Sudan red, poisonous rice, illegal cooking oil, Sanlu milk powder, plastic vermicelli and so on. It becomes a necessary for the mutual poisoning incident in the circumstances that we are seeking to maximize our interests in today in the absence of faith and lack of supervision. There is no doubt that facts discussed above are again and again proved the existence of government failure in the field of food safety supervision, so the new management way is not a moment to be lost to actively mobilize the social forces and explore the multiple management. NGO as the outstanding representative of the third party's power should become an important key to solve this tough problem-food safety. The food NGO is as an emerging force in the field of food safety supervision. Although there is nothing comparable to this superiority in structural design, it ultimately can not escape the destiny that new born things will face numerous unfortunate situations at its birth. Especially, when the development for civil society in China is imperfect and the construction of democracy and the legal system is unsound, the situation of food NGO's role is still not optimistic.

The first problem is small number for it. Although the NGO in China have been established for a short time, who basically started from the time of the reform and opening up, it has developed rapidly. According to the Statistical Report for Civil Affairs Development in 2008, there were 414,000 national organizations and 230,000 national groups in China by 2008. But the national organizations specialized in the food safety were still rare. The association of food industry was established early in China. The most influential and largest association must be China Food Industry Association, which is currently the unique, national and self-regulatory industry management organization for food industry sector. And it has done a lot of fruitful work for promoting the sustained, steady and coordinated development to our food industry. However, it is restricted not only in taking their actions, but also in collecting the social resource with strong administrative color. Even though the regional industry associations such as food industry association in Xiamen and Shenzhen and so on have mushroomed, their influence is relatively small. Some national or even international NGO is also involved in the food-related activities, yet these activities are only sharing a small proportion of all the activities.

The second problem is the weak action force. It is embodied in the following three aspects for the weak power of food NGO. The first is narrow space for its activities (Su, 2012). The Food Safety Law of PROC we are looking, hereinafter referred to the Food Safety Law, was finally implemented in June 2009, which provides a series of procedures and measures for all aspects of food safety regulation as a specialized law for guaranteeing the food safety. But it is regrettable that the law can't give enough space to NGO that participates in food safety management under multiple perspectives. We can talk about this situation in the following two aspects. One is banning NGO from recommending food to consumers. The article 54th of Food Safety Law stipulates that the supervision and administration department for food safety or all agencies that assume responsibility for food inspection, the associations for food industry and consumer associations may not recommend the food to consumers by advertising or other forms. The associations for food industry and consumer are as the important representative to the food NGO. And their major job is to consider how to maximize the protection the legal rights and interests of consumers during the food consumption and to provide consumers with the right and reasonable suggestions. It is not only coinciding with their service aim but also a relatively straightforward and efficient service form. Besides, people will need the guidance of NGO when they are facing the different kinds of food. So it helps the government enormously with the advice and assistance by the food NGO to regulate the food safety. The other one is lacking the provision of public interest litigation system, which refers to the system that any citizen, artificial person or other social organizations all can bring an accusation to the People's court and ask the offenders to suffer the legal liability according to the law when anyone confronted with the action that violates laws, regulations and social public interests. It is apparently of great significance for this system to punish the illegal acts and torts in the industry of food, but it is not mentioned about it in the Food Safety Law. The second is the severe shortage of professionals (Liu \& Wang, 2011). People are both the carrier of all actions and an important key to control operational efficiency. It is also subject to the shortage of people for the food NGO to difficultly develop, which does not mean the small number of volunteers but refers to professional reasons-it is hard to find an expert with professional background in food. On the contrary, many graduates with food major have nowhere to employment. Because the current demand for food professionals is basically saturated in stateowned and foreign-invested enterprises and even though people with work experience is preferred if there is demand. They show their extreme distrust and disagreement to the development platform provided by the food NGO, it is finally the only way for them to get the other jobs or fall into the mire of unemployment. The third is that there is too little money to spend on it. Although the adequate fund is an important guarantee for NGO in the field of food safety to make breakthroughs, it is often in the straitened circumstances for its real life. Apart from the food NGO, some well-known NGOS such as welfare center for children, rescue station, the Red Cross 
Society and so on are also in shortage of funds. It is a major cause of the tragedy for the single channel to finance. According to the analysis of the NGO Institute in Tsinghua University, there are 53 percent of government subsidies, 31 percent of membership fees and revenues, 10 percent of individual and corporate donations, 2 percent of foreign donations and 4 percent of other income in the capital resources of NGO in our country. Because the system of social security is not perfect, there are the tradition for people who are more willing to keep assets for their future generations and the public distrust for the funds operation of NGO, the private and corporate donations do not play an important role in the NGO's funding resources.

The third problem is that it has a narrow and single channel to participate. The food NGO does not form its own voice in the society as insufficient support. About the number of NGO, there is not much difference between China and Western countries, yet Chinese NGO does not keep the same status as Western countries' in the field of social administration. There are two reasons. The first is that the official is relatively unwilling to let NGO participate in public management, because the ways of NGO taking part in the public affairs are mainly organizing the protest of media and the public to put pressure on the government decision, which fundamentally is an indirect participation that does not include public affairs. The second is that the interactive channels between NGO and the public are traditional and single. The ways for NGO to interact with the public are mainly publications, lectures, announcements and other traditional methods, which not only are inefficient and unable to adapt to the ever-changing social situation, but also can not meet the ever growing desire of people for service. Besides, many means of communication are one-way and can neither mobilize the enthusiasm of people nor fully unite the strength of all participation, which leads to little progress in alleviating the information dissymmetry in the food market.

\section{Government Failure in the Food Safety and the Supplemental Role of NGO}

Government failure, which is another important economic theory after the market failure, mainly refers to government's activity are not always as valid as it should be or as it could be in theory, that is to say, it can not always be possible for the government's intervention to achieve the pre-set targets and there are many situations that it is ineffective for the government intervention in the real life or it runs counter to the wishes (Liu \& Wang, 2011). In the field of the supervision of food safety, government failure appears the following main features. 1) Driven by the short-term economic interests or affected by the incorrect view of achievements, the local governments have to make an alliance of interests with the unscrupulous companies, and it will cause the severe damage to the independence of government. When the incidents of food safety happened, the government stands the opposite to customers to voluntarily help the unscrupulous companies overcome the crisis instead of actively representing the interests of customers. Naturally, it has been threatened for the public trust that government accumulated for a long time (Ou, 2010). 2) Restrained by aspects such as bureaucratic thought, hierarchical structure, staff quota restrictions and so on, it seems also slightly insufficient for the government's profession in the field of food safety supervision. For example, the official experts can not meet the growing and diverse needs of reality no matter in quality or in quantity (Su, 2012). 3) As lack of the effective means to break the Parkinson's Law (another name for bureaucracy or bureaucratic phenomenon) and the high institutional cost of administrative act, the efficiency problem of government regulation in the food safety are also widely criticized by people. Many reforms have been made by government, but they failed to get rid of the problems discussed above. The food NGO depending on its unique attributes can effectively play a complementary role in some aspects that government's supervision is less effective, under the background of small government and big society, it has been a trend that public administration takes instead of administrative management.

\subsection{The Independence Supplementary to Food NGO}

The government has granted more and more rights such as the quality testing, the certification authority and so on to the third party-NGO organizations this year, whose independence will provide powerful guarantee for a fair, impartial and reliable test process and result. In other words, its independence is an important key to ensure that NGO will successfully enter in the field of food safety. First of all, the food NGO is not to gain profit as the goal, which greatly ensures its firmness facing with the economic interests' temptation. Secondly, its distribution area is wider if the NGO is more well-known NGO which can be distributed in the national areas or even multinational areas and the NGO's members are not limited to a single specific class. The diversity and complexity of its members, on the one hand, determine the food NGO is both uneasy to be bribed by unscrupulous businessmen and unlikely to be controlled by local government, so it is the real spokesman for public interests. It is more 
important that the food NGO can rapidly take part in as the independent third party to make comprehensive and objective investigation for the truth of the complex events and then timely return the available information to the public and the authorities through the appropriate channels after the outbreak of food safety incidents. All in all, the food NGO is making its contributions in the process of restoring the truth and bringing the illegal behaviors on food to justice. On the other hand, the diversity and complexity of NGO's members also can provide certain strength for food NGO in competing with unscrupulous businesses, its advantage is more obvious especially when the members hold the rich social resources or own the remarkable ability to mobilize the public.

\subsection{The Specialization Supplementary to Food NGO}

It is another advantage for specialization that food NGO has to fight against the illegal acts of unscrupulous businesses. In order to ensure the clarity and effectiveness of its acts, most NGOS have openly set their purpose and goals before establishing it, on which they can depend to selectively recruit and absorb members and then establish a distinctive and professional team. Just as the consumers' association is aimed at protecting the consumers' interests, the Red Cross is aimed at providing medical aids and the Friends of Nature is aimed at protecting the ecological environment, the food NGO also has set its goal to ensure the food safety from its birth. It has always been diverse to the things' development, the association of food industry which owns the unique advantages make itself superior in forging specialization. Taking the association of food industry in the United States as example, its purpose is to realize the safety and orderliness of the whole process for food from farm to dinning table through its autonomy. As it is inspired by this purpose and to maintain the reputation of food industry they are working for, a lot of elites in the food industry choose the associations of food industry that account for a large proportion of food NGO. There are three main advantages for the associations of food industry, one is that they are able to stand out as they have experienced a long-term fierce competition of the market economy and they always keep a high degree of sensitivity and a strong sense of crisis in order to hold their professional status. Another is that these associations who mainly come from the front line of food design, research and development are well versed in the latest development of the entire food industry, so they are worthy of experts and and they can easily distinguish the fake food. The last is that they are more careful in supervising their counterparts than government in order to maintain the competitiveness of their products.

\subsection{The Efficiency Supplementary to Food NGO}

It is probably not the most efficient department engaged in food safety supervision for food NGO, but some of its inherent qualities make it more efficient than government departments. There are four main qualities for it. The first is concentration. This is not to indicate that government itself is not careful and dedicated during the process of food safety regulatory, but it is inevitably leading to less concentration as ambiguous functions and intricate rights and responsibilities of government departments. While the food NGO takes the protection of food safety as its unique goal, and it puts all its energy and all of resources it is able to acquire into realizing this goal. So its concentration becomes the prerequisite of ensuring the efficiency. The second is independence. As we mentioned above that there are lack of external intervention for the activities of food NGO, it is not only saving much time and energy for the food NGO to engage in monitoring the food quality and investigating the fake food, but also making them bravely tell the truth without fear of power. The third is voluntary. Some scholars have clearly stated that Chinese NGO is a non-profit civil organization which is voluntarily made up of the Chinese citizens and carries out their activities according to its rules to realize the common aspiration for its members. This statement indicates that a considerable number of staffs in NGO are providing their services on basis of pursuing the satisfaction of spiritual life, this is both a more efficient and more lasting driving force compared to the material rewards, and explains why some the volunteers have more enthusiasm without any economic rewards than in the case of doing their payable jobs. The last is its nonprofit quality public welfare. The aim of NGO activities has always been increasing the public welfare, even if it sometimes charge a certain fee to its service object, its consideration of social benefits is more than economic benefits. As this nonprofit thought naturally lets it own such widespread social mobility, more and more people devote their money and power to serve the public, and the operational efficiency is therewith growing exponentially.

\section{Solutions}

To give full play to the supporting role of the food NGO in establishing the governance model for food safety 
that is based on mainly led by government regulation in our country, we must successfully address the above challenges we have discussed. So we need to focus on the following points.

\subsection{Further Optimizing the Legal and Institutional Environment of Food NGO}

As we all know, nothing can be accomplished without norms or standers. Laws and institutions are not only a constraint, but under certain circumstances are a safeguard which can ensure both the continuous supply of people and money to the food NGO and guarantee that food NGO will play the active role to maintain the food security in the legal and relaxing environment.

The legal regulation for NGO to enter into the field of food should appropriately be reduced. Firstly, it must be revised and perfected for the Regulations Governing the Registration of Social Organizations, which has been implemented for more than twenty years since October 1998. Now the social conditions have already undergone the enormous changes, so some regulations at that time are now becoming a constraint. For example, the Article XIX of this regulation sets that NGO shall not establish regional branches and the paragraph 5 of Article XIII regulates that two NGOS can not be in the same field, which forms serious constraints for its development to enhance the social influence and strengthen the social mobilization forces. There are also many similar provisions like these regulations, all of these rules should be made some revised with the development of society and time. Secondly, we can learn from the proper experience of western countries. It would be granted the legal identity for participating in public activities as long as NGO was established to register under guaranteeing the freedom of association, if the register system instead of the system for examination and registration. Besides, some measures can also be made like properly breaking the government monopoly to punish the illegal enterprises and so on to make more and more non-governmental organizations participate in the food safety supervision through legal permission.

The food NGO to take part in supervision should be endowed more legal authority. Some NGOS are also making effort in food safety issues, yet its effect is not prominent, which is mainly caused by the shortage of rights in law. A lot of unscrupulous companies relying their wealth and fame always pay no attention to the criticism and denouncement of society. Therefore, it should not only allow more and more NGOS to come into the area of food safety in the law, but also grant them legal authority for participating in food safety supervision. This doing will let the food businesses truly attach importance to food NGO. For example, the German Industry and Commerce has gotten high authority. According to the law in Germany, the enterprises that have be registered by government authorities are the member of the German Industry and Commerce and they should be limited by this organization. They can not freely join it and have no their freedom to retire. If the member violates the provision, German Industry and Commerce will have right to punish it. The German Industry and Commerce will also forcibly deduct certain amount from its account if the member can not pay membership dues on time. The German Industry and Commerce will even deprive it of the rights to get some standard certifications if the member completely disregards the regulations and breaks the rules. It will not only provide the necessary guarantee for its continuous development, but also the great supplement for the government regulation in the efficiency to correct its mistakes by more legal endowment for the food NGO.

The new system should be established for the food NGO to finance and pool the human resources. Firstly, it will be promoted with the help of the system' force for the donation except hoping that more and more enterprises and individuals make self donation for the public welfare in financing. For example, the traditional practice that the rich leave their property to the next generation would gradually be changed if the system for inheritance tax is established. As well as their wealth should be attracted to make a contribution to charity. Besides, the construction of financial control system should also be strengthened to make the funds operation further open and transparent. The food NGO should not only consciously accepted the official supervision such as the state finance departments, auditing departments and so on, but also regularly address the funds' details of income and expenditure to the public and sincerely invite the donor representatives and the public representatives to participate in both the formulation and the implementation of its budget and final accounts to get the public's trust and support. Finally, the social contributions are also encouraged through the tax preference policy and so on. The personnel control system for the food NGO will be established from entering it to out of it in the human resources. According to the voluntary and the professional feature of the food NGO, its members should be classified by full-time or part-time and professional or non-professional to separately manage. The management for the part-time staff should be appropriately relaxed. As long as they have highly their enthusiasms and responsible attitude for the food safety, they should be welcomed to take part in it and the relevant subsidies can even be 
given for them according to their contribution. The management for the full-time staff should be relatively standardized and rigorous, which may include the examination system, the performance appraisal system, the incentive system, the reward system and so on. It is necessary to build the suitable material security system in order to attract more experts in the area of food, which can sweep the experts' worries and further let them put the whole heart in work. And it can be established to the system of personnel exchanging and mutual cooperation with universities and research institutions (Liu \& Wang, 2011).

\subsection{To Create the Diverse and Efficient Participating Channels}

It is only the first step for the construction of legal system to create a diverse and efficient participating platform. It can fundamentally provide more chances and capabilities for bargaining for the food NGO and it is necessary to supervise food security by the cooperation of food NGO and all citizens. Firstly, to build an equal and normalized communicating mechanism with government, which can timely feedback the public wishes and demands to government and expand the food NGO's influence while making the government's action suitable with the public intends (Liu, 2010). Secondly, the food NGO should create more network information platforms under the information era, and the special platform even can be set up for an influential food safety event. These will greatly improve the opaque situation for information in food industry and make the bad companies have nowhere to hide. The Green Peace organization has well exemplified for us that owns a project of pesticide residues for fruits and vegetables. Since 2009, it has annually invited the relevant personnel in the food safety industry to check regularly the sampling tests for two to three times to the fresh fruits and vegetables in supermarkets and the test report and the supermarket ranking list are made according to the result for sampling test each time. And these information will be issued the official website of Green Peace the consumers can read the information through it. All of these actions have both increased its social influence and improved its service efficiency. Lastly, to build a mesh participating network with the help of new media such as web, fetion and so on. Each consumer is a food safety warden who can participate in the activities of food safety supervision. As long as the illegal actions related to food safety were found in the daily consumption, they could take advantage of these communication media to send their information to the food NGO. And the testing procedures for the food NGO will be quickly started to faster and more efficiently enter the battle for defending food safety. Certainly, the realization of this idea also needs the further improvement and supporting of communication system.

\section{Conclusion}

Although we have been taking action in our country for the food supervision and some achievements have also been made, there is no doubt that facts discussed above are again and again proved the existence of government failure in the field of food safety supervision, so the new management way is not a moment to be lost to actively mobilize the social forces and explore the multiple management. In short, the food safety is the cornerstone of social development and is an important manifestation of social sustainable development. Facing the food safety supervision, if we really properly solve this problem, on the one hand it is extremely urgent, on the other hand we have a long way to go. NGO as the outstanding representative of the third party's power should become an important key to solve this tough problem—food safety. Therefore, the food NGO might be worth a great deal; it is essential for the system construction especially the construction of relevant Law apart from continuous development and ceaseless accumulation.

\section{References}

Liu, Q. Y. (2010). Research for the NGO's Role in the Food Safety Management. Changsha: Hunan University, 32-34.

Liu, Y. G., \& Wang, F. L. (2011). The Politics of Scale Analysis of Sanlu Milk Powder Incident. Acta Geographica Sinica, 10, 84-85.

Ou, Y. J. (2010). Study of the Social Intermediary Organization's Role in the Food Safety Supervision. East China Economic Management, 1, 101-103.

Su, M. H. (2012). Study of the Third Party Audit Mechanism to the Food Safety in USA. Journal of Beijing Administrative College, 3, 69-70.

Su, Y. L. (2012). Research for the Food Safety Governance and Its Enlightenment in the Time of American Progress. Guilin: Guangxi Normal University, 40-43. 
Scientific Research Publishing (SCIRP) is one of the largest Open Access journal publishers. It is currently publishing more than 200 open access, online, peer-reviewed journals covering a wide range of academic disciplines. SCIRP serves the worldwide academic communities and contributes to the progress and application of science with its publication.

Other selected journals from SCIRP are listed as below. Submit your manuscript to us via either submit@scirp.org or Online Submission Portal.
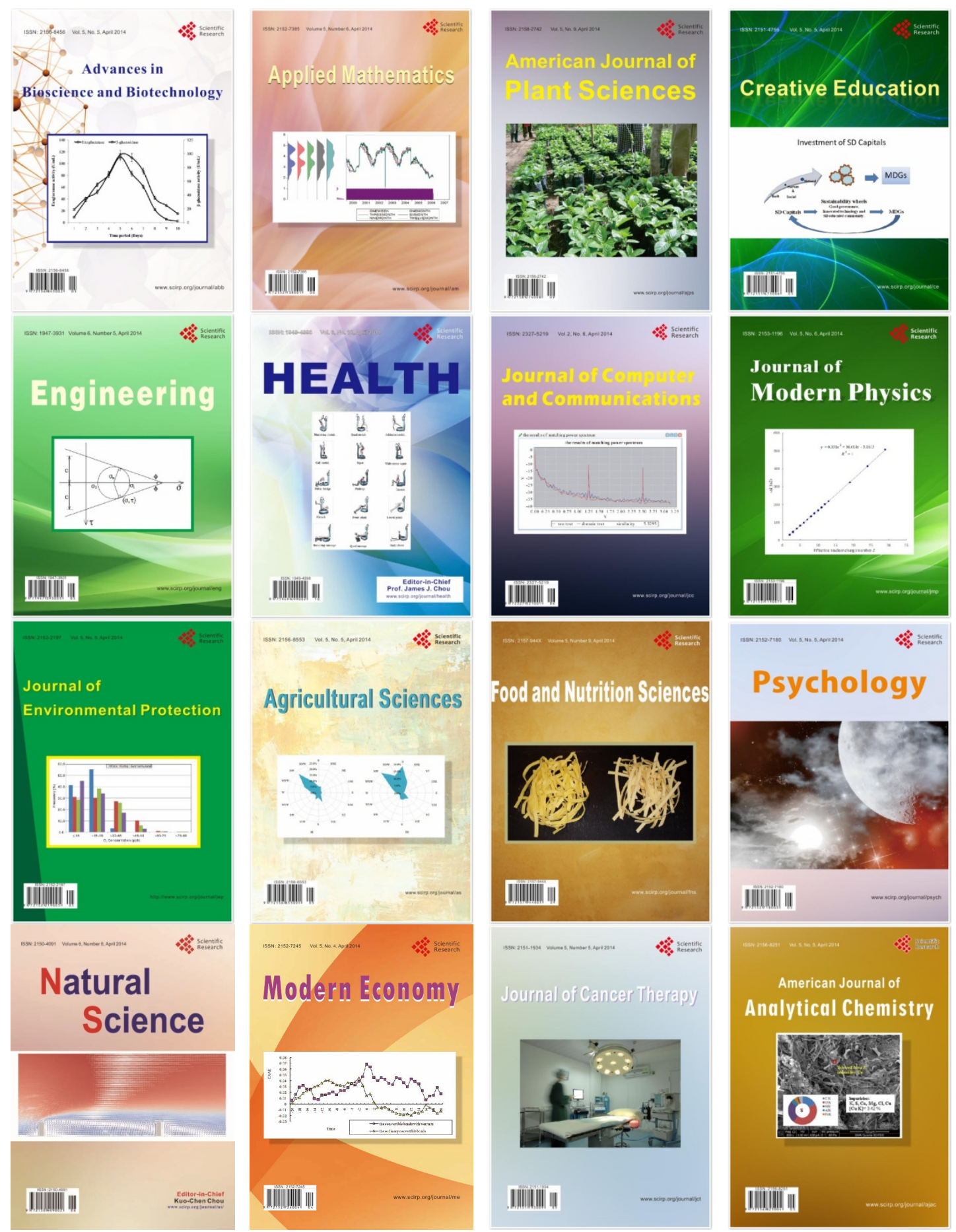